\title{
On Satisfying Duties to Assist
}

Christian Barry and Holly Lawford-Smith

Most effective altruists and indeed most ordinary people think that we have duties to assist people in severe need, and that these duties can be satisfied. They think that a person is morally required to do something to help others in need, but that at some point she can refuse to do more on the grounds that she has already done enough. They may allow that some emergencies and instances in which agents can prevent catastrophic risk are exceptions to this: it may always be wrong to refuse to help in situations of this type, at least when one can do so without significant additional sacrifice. But what makes it the case that a person has satisfied her duties to assist in other kinds of cases? This question is of practical importance: determining how we can satisfy our duties to assist is important for each of us who is working out what we ought to do, as well as for gauging whether others may be liable to moral criticism or other sanctions on the grounds that they are not doing enough.

Duties to assist are justified by the importance of the end of helping those in severe need, so one natural thought is that a person has satisfied her duties to assist when she has succeeded in securing enough good for such people. Such a position is suggested by Frances Kamm. Kamm observes that a "moral moderate" may, at least in cases where she has already promoted a lot of good, deny that there is even a reason to promote the greater good.1 But is this plausible? Suppose that her blood contains a rare antibody, so that when she gives blood she ends up saving many hundreds of people's lives. It costs her next to nothing to donateshe doesn't find it unpleasant, or costly in financial or other terms. Here it would be unreasonable for her to refuse to help others in the future by citing how much she has already done.2 One might suggest, alternatively, that she has done enough when she has taken on a certain amount of cost to help others in severe need. After all, many have

1 Kamm (1992, p. 356).

2 Our example is not entirely fanciful. An Australian named James Harrison possesses blood with an antibody effective against rhesus disease (which causes pregnant mothers' blood cells to attack their foetus's blood cells), and whose blood donations have allegedly helped millions of people. However, Harrison himself has a strong aversion to both pain and the sight of blood; each blood plasma donation comes with some physical and psychological discomfort for him, so the costs to him of his efforts may not be so minimal to him as they are in our imagined case. Edwards (2015). 
supposed duties to assist to be limited by an agent's so-called "appeal to cost," so perhaps these duties are satisfied when the cost hits a level at which she can make such an appeal. But this simple solution is also inadequate. If a person donates 15 per cent of her income to save one person in need when she should have known that the effort would be in vain, because that person would be saved in advance via other means, she has squandered her resources without satisfying her duties to assist. But if satisfying these duties is not simply a matter either of success or of sacrifice, then what is it a matter of?

In this article, we attempt to make some headway in answering this question, which to our knowledge has been touched on but not systematically engaged with in the literatures on duties to assist and effective altruism. We will consider a number of factors of an agent's behaviour that might be thought to be either necessary or sufficient for her to have satisfied her duties to assist. We shall propose that whether a person has satisfied her duties to assist depends not on any single factor but on a complex interplay of several factors. These are the costs she takes on for this purpose, the connection (via the agent's beliefs and intentions) between the costs taken on and the outcomes to be achieved, the importance of the outcomes_-various people helped in different ways — to be achieved, and the success of her efforts. A principal aim of effective altruism is to encourage people to pay greater attention to how efficient their expenditures are in addressing the needs of badly off people. 3 In the concluding section of this paper we explore whether we should go further, and incorporate a doctrine that inefficiency in expenditures can reduce or eliminate the degree to which such costs count towards satisfying duties to assist.4

\section{Inputs: cost}

What makes it seem unreasonable for a person to refuse to do more in the case of giving blood introduced above seems to be that, while she has done a lot of good, the agent has taken on precious little cost for this purpose (assuming, again, that she doesn't mind having

3 See, for instance, MacAskill (2016, pp. 14-15).

4 There might be such a requirement on other sources of duties too, such as duties that arise from being a beneficiary of injustice. We won't explore that possibility here. We recognize that there may be good reasons why the effective altruism movement might resist extending their concern with efficiency in this way. 
her blood drawn). Taking on cost is not sufficient to satisfy a duty to assist, but it seems at least to be a necessary element for its satisfaction. A great deal of the literature on the duty to assist concerns just how much cost we are required to take on to help others in severe need.5 Curiously, there has been relatively little discussion of precisely which costs are relevant for such calculations.6 So we'll explore some options.

\section{$1.1 \quad$ Utility}

Perhaps the relevant cost is loss of utility, broadly understood. On this view, taking on utility loss to some threshold to help others in severe need is the cost element in determining whether these duties have been satisfied. This approach seems implausible. Consider a miser; he deplores spending money and above all giving it to charitable causes. It causes him great distress to make even very small financial contributions to charitable organizations. Has a wealthy miser satisfied his duties to assist once he makes some meagre contribution, simply because this costs him the right amount of utility? Surely not.7 Nor does sacrificing utility seem a necessary condition for satisfying them. Consider a person who has always experienced strong and unconditional empathy with human suffering. This person decides early in life to pursue a career in medicine, and after her medical education is complete, spends much of her time volunteering with the International Medical Corps (IMC), working in conflict and disaster zones around the world, while working part-time to support herself. She enjoys her volunteering work more than the financially lucrative opportunities for full-

5 See for example Garrett Cullity's detailed analysis of more or less extreme demands that duties to assist can be interpreted as imposing on agents. Singer (1972) and Unger (1996) have famously argued that such duties impose extreme demands on us, while Cullity himself defends the view that duties to assist are only moderately demanding, though he notes that they still "demand more of us than many of us find comfortable." Cullity (2004, p. 3).

6 Note that this issue parallels but is distinct from the discussion in the literature regarding the 'currency' of egalitarian justice or 'equality of what' debate: see Dworkin (1981a), (1981b), Cohen (1989), Sen (1980), Nussbaum (1992), Rawls (1971). That debate concerns whether individual advantage should be conceived in a theory of social justice in terms of utility, preference satisfaction, capabilities, social primary goods, or some admixture of these elements, and whether egalitarians should strive to achieve equality of one or another of these goods. The debate we engage with, on the other hand, concerns the kinds of costs that are relevant to satisfying duties to assist. Capabilities or utility, for example, may offer plausible approaches to assessing individual advantage in the context of a theory of social justice but be seriously flawed as accounts of the relevant cost for determining whether duties to assist have been satisfied.

7 Our objection to utility as the appropriate metric for cost in assessing duties to assist has affinities with Dworkin's 'expensive tastes' criticism of welfare as the appropriate goal of egalitarian theories. "Equality of welfare seems to recommend that those with champagne tastes, who need more income simply to achieve the same level of welfare as those with less expensive tastes, should have more income on that account. But this seems counterintuitive." Dworkin (2000, p. 48). 
time work in local practices that she could otherwise take up. She suffers no loss in utility in volunteering for IMC—-she would find it tedious and unfulfilling to work full-time in ordinary medical practice — and yet seems a paradigm case of someone who has satisfied her duties to assist (indeed, may have far exceeded them).

\subsection{Interests}

Shelly Kagan maintains that the relevant 'cost' is an individual's loss of ability to promote her own interests, subjectively understood.8 The relevant interests need not be selfish; an individual who happens to have an interest in volunteering at a local homeless shelter might pay a cost when she is asked to volunteer for a charity working on humanitarian relief for natural disasters instead, because the latter affects her ability to do the former.9 There are several problems with characterizing cost in this way for our purposes. First, it doesn't leave room for counting expenditures (e.g. of time, of money) as costs when they don't set back our interests. This seems counter-intuitive. Consider again our IMC volunteer. She passes up other opportunities because she finds the work with IMC exciting, challenging, and rewarding. She is in an intimate community with the other medical staff and volunteers. She feels good about her decision.

On Kagan's account, this person's activities wouldn't count towards fulfilling her duties to assist, because they cannot be characterized as a 'cost' to her, as he understands it: the relevant cost is a person's loss of ability to promote her own interests.10 But in this case, it seems to be one of the person's interests to address the severe needs of those trapped in places that few others dare go. In taking up this project, she is simply pursuing her interests, and so has suffered no loss in her ability to promote them. Yet, as already noted, this seems a paradigm case of efforts that should count towards satisfying a duty to assist.11

\footnotetext{
8 Kagan (1991a, p. 233; see also 1991b). In a similar vein, Cullity refers to the costs imposed by duties to assist in terms of sacrifices of "sources of personal fulfillment" in our lives. Cullity (2004, p. 70).

9 Kagan (1991a).

10 Kagan (1991a).

11 In his recent book Singer makes a related point. He defines "effective altruism", and comments: "That definition says nothing about motives or about any sacrifice or cost to the effective altruist ... [W]e should not think of effective altruism as requiring self-sacrifice, in the sense of something necessarily contrary to one's own interests. If doing the most you can for others means that you are also flourishing, then that is the best possible outcome for everyone" (Singer 2015, p. 5). See also Andreas Mogensen, Will MacAskill, and Toby Ord (2017).
} 
This suggests that the costs that are relevant to duties to assist should be sensitive to expenditures of the relevant sorts regardless of how they interact with the interests of the assister. That is, our IMC worker's time and energy should be costs that count towards her satisfying her duties to assist. Indeed, to deny that undertaking such costs counts towards satisfying these duties seems to embrace a view of morality in which conduct isn't moral unless it is unpleasant or otherwise counter to the preferences or inclinations of the person engaging in it. This is not a very appealing view of morality.12 One could perhaps argue that, although the IMC volunteer's conduct is morally praiseworthy, the fact that she incurs no setback to her interests through her work means that this work should not count, or not count as much towards her satisfying her duties to assist. That is, we can praise her choices consistent with maintaining that she needs to do more in order to satisfy her duties to assist. But this implies that if she didn't do more, she would be criticizable for failure. That strikes us as counter-intuitive.

Kagan's view also implies that there would be large differences in what duties to assist require of different people who seem similarly situated in all morally relevant respects. Take a person who managed to internalize a positive disposition towards the expenditures she was making in service of those in need, so that these expenditures came to be aligned with her interests. The initial cost of overcoming the aversion would count as a loss of ability to pursue her own interests, but, once she had internalized new positive dispositions, those costs would be in line with her interests, and so not count towards discharging duties of assistance on Kagan's account. In that case, more could be asked of her. This would mean that she could be required to do a great deal more than another person who made no such efforts.13 Generally we think that internalizing certain attitudes, values, and dispositions is a valuable means towards more ethical behaviour.14 This gives us further reason to count expenditures of the relevant sorts towards satisfying duties to assist, regardless of how they affect the assister's interests.

12 A view of this sort is often attributed to Kant, though many of his interpreters consider this to be a misreading of his view. For discussion see Herman (1981), and Baron (1984).

13 Taken to an extreme, this could even create perverse incentives in people to not internalize a positive disposition towards certain charitable contributions. 14 See, for example, discussion in Jamieson (2007). 


\subsection{Material costs}

In discussing the utility view and Kagan's view focusing on interests, we've implicitly been alluding to other costs that agents can take on which do not directly relate to their interests, though they can certainly be relevant to their pursuit of those interests. But exactly what kinds of costs are these? Kagan himself suggests "money, time, effort, and life itself".15 We'll say more about each of these in turn.

When organizations attempt to give a specific content to our duties to assist, they often frame them in terms of financial expenditure. For example, the organization Giving What We Can invites people to donate 10 per cent of their incomes, while in The Life You Can Save Peter Singer specifies a progressive scale of giving and invites people who earn more to give more.16 Taking on monetary cost certainly seems relevant to satisfying duties to assist. Just how this input should figure in our assessment of whether someone has satisfied their positive duties is more difficult (we'll return to this issue below).

Of course, all the money in the world would count for little, in terms of assistance, if there weren't people either willing to be paid to administer the assistance, or willing to do so unpaid. Money can buy material resources (materials to build houses and shelters, blankets and clothes, food and drink, medical supplies), and it can help people to deliver them. But it is not the whole story. Time and effort (or labour) are a crucial part of the story too, and taking on these costs too seem relevant to satisfying duties to assist.

What about physical costs? Some people would accept that there are extreme cases in which a person might be required to sacrifice her own life to save a significantly greater number of people. So if the stakes are high enough, there might be a duty of assistance to accept the loss of one's own life. (For example, imagine that a billionaire proposes to donate sufficient money to permanently end global hunger on the condition that he be allowed to murder you.) But setting these improbable cases aside, is it plausible that we can have duties to assist whose fulfilment requires the input of physical sacrifice?

If we can, then the satisfaction of duties to assist can also be measured, at least in part, by such sacrifices. And it seems sensible to discuss duties to assist in physical terms,

15 Kagan (1991a, p. 233; see also 1991b).

16 See https://www.givingwhatwecan.org/pledge/ and Singer (2015, pp. 19-20). 
counting towards their satisfaction, for example, the bruise, broken finger, or lost arm brought about in the course of a rescue or an intervention to prevent assault. In discussing the question of how much a person can be required to sacrifice in order to save a child, Barry and Øverland include being asked "to have your hair cut", "to suffer a kick in the leg", to "sacrifice a finger", to "lose a leg", to sacrifice "a hand, an arm, or a leg".17 Singer discusses the donations of blood, bone marrow, and kidneys.18

Although these material costs we've been discussing are themselves objective, it seems that any plausible way of specifying how much of these costs agents must take on to assist others should take account of how the agents will be affected by such sacrifices. We noted that taking on monetary cost is relevant to satisfying duties to assist. However, determining how much particular monetary costs should count towards satisfying an agent's duty to assist is complicated by the fact that small amounts of money typically mean more to poorer people than to richer people. Intuitively, the poor person does more to satisfy their duty to assist through contributing $\$ 100$ to poverty relief than does a very wealthy person. We shouldn't accommodate this by making assessments of costliness entirely subjective and dependent on the individual psychologies of those giving. A very wealthy miser may experience a small contribution as very onerous or find it motivationally difficult to provide it, but should we regard such aversions as relevant to his satisfaction of his duties? 19 We don't take such things into account to determine which particular rates of taxation are fair.20 And this is not just because having a tax system that was tailored to the specificities of particular tax subjects within some income group would be impracticable, but because it would seem unfair to do so. The most plausible solution, in our view, is to appeal to (admittedly rough) shared understandings of how people should reasonably be affected by different material sacrifices. For example, many people would regard a poorer person's

17 Barry and Øverland (2013, pp. 196-7).

18 Singer (2015, ch. 6).

19 Our attitudes towards such cases may be different if we regard such aversions as entirely outside of the control of the agent. As Wolfgang Schwarz pointed out to us, if a person was "wired up" such that every time they made small contributions to help others they were caused to feel tremendous anguish and they were completely powerless to cultivate different dispositions, this (subjective) cost would seem relevant to what we could reasonably require them to do. But ordinarily we do not treat such aversions as hardwired into people in this way, even when we recognize that their upbringing and other features of their environment played a substantial role in the formation of their preferences and aspirations.

20 Thanks to Laura Valentini for the example. 
donation of 20 per cent of her income to be quite onerous, and a very rich person's donation of 20 per cent of her income to be not particularly onerous. This is true even if some particular rich person experiences the donation as a very serious imposition while a particular poor person does not. Our views about whether any given contribution to help others can reasonably be regarded as onerous are based partly on what we think most people do in fact find onerous.21 But they are also based in part on our commitment to demanding that people cope with some of their personal idiosyncrasies when it comes to conforming to social standards for conduct.

We conclude, then, (i) that the 'cost' inputs should be regarded as plural and objective, including money, time, effort, and physical sacrifice, rather than subjective; but (ii) that how much these costs should count towards an agent's satisfaction of her duties should depend on common social understandings of how individuals variably situated should reasonably be affected by them.

\section{Characteristics}

So far, we've been focusing on the costs people take on to assist others in need. But what about what a person believes and intends about these expenditures? We might think that the state of an agent's mind is relevant to whether taking on some cost counts towards satisfying their duty to assist. One possibility would be that the agents must intend that the cost they take on be to help others in need. The relevant intentions might be understood restrictively or permissively. On the restrictive understanding, the costs an agent takes on must be for the primary reason of helping the people in need. The restrictive reading seems too strong. Consider a person whose primary motivation for contributing effort and resources to helping the poor is that doing so is an effective means of eliciting esteem from others. He gives a very large proportion of his income to effective charities. Such a person's efforts seem to count towards the person's satisfying his duties to assist, even though we might be reluctant to praise his character. So too with the person who gives primarily to avoid a sense of moral guilt at doing nothing, rather than out of any genuine concern for the beneficiaries.

21 For a related discussion see McElwee (2017). 
On the permissive understanding, all that is required is that agents intend to help others, even if this is not the primary reason for their action-the esteem-seeker and guilt-avoider intend to help those in need, even if this is only a side effect of their primary motivations. This seems largely correct, but needs one slight amendment if it is to avoid being too restrictive. Imagine a state that taxes its citizenry heavily to help the poor abroad. This should count towards their duties to assist being fulfilled. Yet it may be that some citizens are not aware of (or perhaps are not happy about) the fact that some of their resources are being used in this way. Of course, in this case there is still a collective agent (the state) to which the intention of assisting those in need might be attributed, or at least some individuals (other citizens and officials supporting the expenditures) who have the relevant intention. But that is not the same as the person who is taking on the cost-by way of her taxes-intending that her resources be used for this purpose.

This suggests that the duty to assist can be delegated in such a way that the requirement on intention falls on the agent the duty is delegated to, rather than the delegating agent. In those instances where individuals have delegated (voluntarily or not) their duties to assist out to the state, there is no requirement on the individual (although there will be on the state) to take on cost with the intention of assisting. But where individuals have not delegated duties to assist to their state, it is important that there is, in the background, some aim to assist. If a businessman makes an expensive investment from which he hopes to profit, but instead loses his money with the unintended and unforeseen consequence that some people in need are helped, this wouldn't seem to count towards his satisfying his duty to assist-it's just a bad investment that happened to have good consequences for people in need.

Our proposal, then, is that an agent's beliefs (or the beliefs of those acting on their behalf, in case their duties to assist have been delegated), first about the connection between the inputs and success, and second about the value of the assistance provided, are relevant to determining whether they have satisfied their duties to assist. We are not claiming that the agent's beliefs about connections between inputs and success must be true, only that they be reasonable (i.e. responsive to the readily available evidence). First, the agent must believe the expenditure to be a means to assistance. This is closely related to our discussion of 
intentions above; if the businessman lacks any awareness that his investment will assist people in need, then the fact that it happens to deliver benefits seems to be irrelevant to whether he's satisfied a duty to assist.

The proposed requirement to be responsive to the readily available evidence means that an agent must consider whether the recipient of assistance is likely to benefit from what she seeks to provide them with. Current practices are not always responsive to evidence in these ways. People who seek to assist others may fail to consult with the intended beneficiaries, and consequently may give them things they don't need or want, or even things that are counterproductive to their getting what they need and want.22 When this happens, even agents that have taken on a lot of cost to help others may not count as having satisfied their duties to assist.

Suppose a person lacks a reasonable belief that her expenditures will connect to assistance, but has an intention to help. If her expenditures fail to secure assistance, it seems she will have failed to satisfy her duties to assist. But suppose that her expenditures do secure assistance. Will she then also have failed, or should success, even lucky success, count towards the satisfaction of duties to assist?

\section{Success}

So far, we've argued that the satisfaction of duties to assist consists in expenditures of money, time, effort, life, and limb, made with the right intentions and beliefs. But it seems to us that success should count too. In considering whether we can reasonably ask a person to do more, it seems clear that we should take account of their success. Someone who has secured a lot of assistance with the intention of helping may have done enough. If we're right about this, then satisfaction is disjunctive: one satisfies the duty to assist either by successfully providing assistance (with the intention of helping, but without a reasonable belief that the expenditure will actually help); or by failing to provide assistance while intending to help and having the reasonable belief that the expenditure will actually help. Should inefficiency in expenditures reduce or eliminate the degree to which such costs count 
towards satisfying duties to assist? Of course, expenditures can be more or less inefficient depending on the degree to which they fall short of maximally efficient expenditure. So the idea would be that at least some degree of efficiency is a necessary condition of some expenditure counting (or counting fully) towards the satisfaction of an agent's duty to assist. A requirement of efficiency is a requirement to not merely assist, but to assist in ways that make efficient use of one's expenditures.

One practical objection to any sort of efficiency requirement on giving is that people who succeed in assisting others-no matter how inefficiently-are still doing more than most people (most people do nothing), and telling them that they should be doing even more risks backlash - turning people off the idea of giving. As a matter of strategy, it should be those who don't assist at all, rather than those who assist inefficiently, that we should target. Our discussion here, however, focuses not on figuring out what we should tell people about what they ought to do when it comes to duties to assist; we're asking what they ought to do. That means exploring how duties to assist should be understood, even if it would be wiser to keep quiet about certain of their features for strategic reasons.23 A theoretical objection might come from those who regard all assistance as supererogatory: to be commended, certainly, but not strictly required. Those holding such a view might argue that for that reason, any assistance is a good thing, and there's nothing to be said (apart from purely evaluative claims about what would have been better and worse states of affairs) about the different causes people choose, if they choose any causes at all, and the different means to pursuing those causes. Because assistance is supererogatory, on this view, there's no room to criticize those who do not provide it as failing in any duties, and there's certainly no room to criticize those who do provide it for failing to do something even better! It is questionable whether efficiency requirements are indeed out of place when it comes to supererogatory action. Pummer, for example, has argued that there are strong requirements of efficiency even in this case.24 In any case, our discussion here is addressed to those who share our view that

23 See Sachs (Chapter 9, this volume) for discussion.

24 Pummer presents an interesting case-Arm Donor-in which we are invited to consider an agent who can intervene to prevent harm to others at the cost of an arm. He suggests that, even if a person's decision to intervene at this cost would be supererogatory, he must be efficient in preventing harm should he choose to intervene. If he can intervene at the cost of an arm to save one or a hundred strangers, but not both, he is morally required to save the hundred Pummer (2016, p. 83). 
there are duties to assist, and thus also hold that a requirement of efficiency cannot be incoherent in this way.25

An efficiency requirement might be interpreted in three broadly different ways (we'll draw attention to many further complexities below). It might be interpreted in a fact-relative way, requiring that the expenditure of resources actually be efficient. Or it might be interpreted in a belief-relative way, requiring the agent to have acted efficiently relative to her beliefs. Or, finally, it might be interpreted in an evidence-relative way, requiring the agent to have acted efficiently relative to the evidence that she had or should have had available when making her choice.

Fact-relative efficiency doesn't seem a plausible requirement. Suppose that while a financial donation to the Against Malaria Fund (AMF)—which distributes long-lasting insecticidal nets (LLINs) in developing countries-would ordinarily have been (and would be known to have been) an efficient means to assisting others, on one occasion it turns out to be very inefficient (because, say, so many people were donating to AMF when you gave that their servers crashed without warning, and in restoring them the transaction went missing). In this case, you would have taken on cost and had the right intentions and beliefs. We think you would have done all that we might reasonably ask of you. It would be wrong not to count the costs you took on when considering whether we could reasonably ask more of you, despite your lack of success.

Belief- or evidence-relative efficiency do not appear to be plausible requirements either. Consider a person who doesn't choose what they believe will be efficient or doesn't choose what the available evidence suggests will be efficient, but nevertheless takes on cost with an aim of assisting those in need and chooses an option that turns out to be (factrelative) efficient. We might criticize the person for failing to do their due diligence, but that is a separate matter from whether the costs they have taken on count towards satisfying their duty to assist. Would we say that just as much could be demanded of such a person to help others as could be demanded of a similarly well-off person who has not taken on any cost at all to assist others? This seems counter-intuitive. Our rejection of this requirement leaves

25 See McMahan (2017) and Frick (2017) for critical discussion. Note that the debate about whether there are efficiency requirements when it comes to giving supererogatorily remains pertinent whether or not we affirm that there are genuine duties to assist. 
open whether we would want to count inefficient expenditures as counting to the same degree as efficient expenditures—we'll return to this issue below.

So far, we've been considering the idea of an efficiency requirement quite generally. But there are different more precise ways any such purported requirement might be specified. On a first, minimalist understanding, this would be a requirement not to be grossly inefficient (not to choose very inefficient means of providing assistance); moderately, there might be a requirement to choose within a band of causes or courses of conduct of roughly equivalent efficiency (for example, to choose one of the ends generally thought to do a lot of good, but among which there is uncertainty or room for reasonable disagreement over exactly which is the best); and strongly, there might be a requirement to choose the most efficient means to providing assistance. An efficiency requirement might be applied only to the ends chosen, it might be applied only to the conduct pursuing those ends, or it might be applied to both.

For example, we might think that individuals have relatively broad discretion in choosing among candidate causes when trying to satisfy their duties to assist (e.g. they are free to choose animal rescue shelters over children's education charities), but are required to do what will best achieve the ends they choose.26 Or we might think they do not have such freedom: they must choose which candidate duties to assist to take on by choosing the ends that will do the most good, all else being equal (e.g. if donating money to, or volunteering for, charities working against factory farming does more good than donating money to, or volunteering for, animal rescue shelters, then individuals should assist the former).27 Finally, we might endorse both: all else being equal individuals must choose the most efficient means to the most important ends. 28

26 One worry about this proposal is that it is sensitive to how causes are individuated-we return to this point below.

27 See discussion in Pummer (2016) and Singer (2015, ch. 13, esp. p. 138).

28 Singer (2015) discusses the value of donations to art galleries and museums compared to donations to interventions on mortality or morbidity. He argues that even if we don't take the line that no amount of enhanced aesthetic experience of gallery visitors can justify any amount of physical suffering (see esp. Scanlon (1998)), we can still compare visiting the gallery as it is (without the upgrades allowed by any bequest) and alleviating someone's suffering, against visiting the upgraded gallery and not alleviating someone's suffering. He concludes that "you'd have to be nuts" to choose the former. Singer (2015, p. 120). 
Disagreement about whether individuals should have discretion regarding the ends to which they direct their efforts to assist connects to deep controversies in moral theory. We clearly cannot settle such controversies here, but it is worth considering further the forms that an efficiency requirement might take.

Note first that none of the arguments that might be offered in defence of allowing a person discretion in the ends they wish to promote justify a person's taking inefficient means to a given end once she has settled on that end. A person who takes the mitigation of child poverty in Africa as her end but chooses to give her money to an NGO that is much less efficient than other organizations in bringing about this end, for example, cannot appeal to any of these reasons to justify her choice. If there is a requirement of efficiency, then perhaps it applies more unequivocally to the choice of means rather than of ends? But there are some serious difficulties with a view that places efficiency requirements on means. First, determining whether someone has used inefficient means towards some end may not be straightforward. A person's ends can ordinarily be described in a more or less coarse-grained way. If Mischa sends resources to an NGO that is working in Bangladesh, her end could be described as that of helping poor people throughout the world, or it might instead be described as helping the poor in that region. The same means might be efficient with respect to helping the poor in that region, but inefficient with respect to helping poor people in the world at large, so long as it is possible to protect more poor people more cheaply in other parts of the world, e.g. in parts of Africa.

Perhaps this concern can be dealt with by saying that the relevant end is what really motivates the agent—what she actually cares about. Mischa seems to be the only person who can tell us which is the more apt description of the end that she is actually seeking to achieve through her efforts. However, there is an even more serious worry about such a view. It seems odd that, when Mischa's aim is helping the poor throughout the world, her contributions to the NGO she chooses count less towards fulfilling her duties to assist than if her end were instead trying to help the poor only in Bangladesh. If anything, we might regard the broader end as in some sense more praiseworthy, since it targets people in severe need independently of where they may live. In this case it also seems implausible that the value of the ends is somehow incommensurable. 
One interesting upshot of committing to some efficiency requirement with respect to duties to assist is that it would give us greater scope to say something about responsibility. Imagine three different individuals: one chooses to donate money to a university that already has a hefty endowment; the next donates to the most effective NGO working for pay equity between men and women in Canada; and the last donates to the most effective charity working against the spread of malaria. The first is not efficiently promoting the good in either her chosen end or the means of pursuing it. Privately-funded tertiary education is comparatively low priority as a need which assistance might meet, and if a person's chosen end is tertiary education she should pick a university that is underfunded or otherwise struggling to survive. The second chooses an end that is only moderately important (because both men and women in Canada are very well-off compared to most of the rest of the world), but is efficient in her means of pursuing it. The third is arguably maximally efficient in both the end she chooses, and the means she takes to it.

We find intriguing the proposal that only the third has satisfied her duties to assist, although we do not have the space to defend that proposal here. (We don't take a position here on a more moderate version of this proposal, say, that only the second and third have satisfied their duties to assist.) Expenditures that would normally take an individual up to the satisfaction of her duties to assist—-the point at which it would be unreasonable to ask her to do more-do not count as reaching that limit if they are inefficient to some degree. That gives us scope to assign further duties in such a case. Possibly the 'shortfall' between what was accomplished with the actual expenditures and what would have been accomplished with more efficient expenditures is still owed by the inefficient assister.

Singer discusses this kind of requirement, but his focus in that work is on describing the effective altruist movement rather than defending the claim that individuals are required to do the most good they can do.29 Furthermore, he explicitly allows for understanding 'the most good' as the most good you can do (indexed to internal factors, taking a specific person with her talents and capacities). That makes it unlikely that he would go all the way to a strong requirement of efficiency, which looks to be focused more on external factors (how

29 Singer (2015). 
much good different means to the same ends produce, and how much good different ends produce relative to one another).

\section{Conclusion}

We have argued that there are three factors that are relevant in determining whether an agent has satisfied her duties to assist: inputs, characteristics, and success. We showed that the 'inputs' that can count towards satisfying such duties are plural, including money, time, effort, body parts, and even life itself. We argued that in terms of 'characteristics' there must be an intention to assist in the background (even if only as a side effect) of the actions undertaken, and a reasonable belief that the actions are a means to the end of assisting those in need. Actually assisting others could be sufficient for a person's satisfying her duty to assist (provided she has the relevant intentions). But we also concluded that it is not necessary, since a person who does what her evidence or reasonable beliefs tell her will provide assistance can count as satisfying her duties to assist even if it turns out that she has not succeeded in helping anyone.

We considered as an exception to this rule the person whose beliefs were formed in a particularly egregious way, noting that such a person may not count as satisfying her duties to assist even when she takes on substantial cost. Finally, in discussing 'success' we argued that those who take maximally efficient means to important ends (with the caveats just given for inputs and characteristics) will satisfy their duties to assist. However, those who choose unimportant ends, and particularly those who take highly inefficient means to whichever ends they have chosen, can thereby be candidates for having the costs they have taken on discounted, such that they come to have further duties to assist (to make up the shortfall between the assistance they did secure and the assistance they could have secured).30

30 An earlier version of this paper was presented at the 'Ethics of Giving' conference at the University of St. Andrews, the 'Responding to Global Poverty' conference at the University of Oslo, and in seminars at the Australian National University, University of Edinburgh, and University of Adelaide. We are grateful to the audiences at those seminars for their critical comments, and especially to Hilary Greaves, Theron Pummer, RJ Leland, and Garrett Cullity for detailed written comments on earlier versions of this paper. Work on this essay was supported by a grant from the Australian Research Council. 


\section{References}

Baron, Marcia. 1984. “The Alleged Moral Repugnance of Acting from Duty.” Journal of Philosophy 81 (4): 197-220.

Barry, Christian. \& Øverland, Gerhard. 2013. “How Much for the Child?” Ethical Theory and Moral Practice 16 (2013): 189-204.

Cohen, Gerald. “On the Currency of Egalitarian Justice.” Ethics 99 (1989): 906-44.

Cullity, Garrett. 2004. The Moral Demands of Affluence. Oxford: Oxford University Press.

Dworkin, Ronald. 2000. Sovereign Virtue. The Theory and Practice of Equality. Cambridge:

Harvard University Press.

Edwards, Ashton. 2015. 'Man with the "golden arm" has saved the life of 2 million babies." Fox13Now, 9 June (Accessed 8 February 2015). Available at

https://www.npr.org/sections/thetwo-way/2018/05/14/611074956/australias-man-withthe-golden-arm-retires-after-saving-2-4-million-babies.

Frick, Johann. 7 April 2017. "Critical Précis of Theron Pummer's 'Whether and Where to Give.”' Available at http://peasoup.us/2017/04/philosophy-public-affairs-discussion-peasoup-theron-pummers-whether-give-critical-precis-johann-frick/.

GiveWell. November 2014. Against Malaria Foundation. (Accessed 10 May 2015). Available at http://www.givewell.org/international/top-charities/AMF.

Herman, Barbara. 1981. "On the Value of Acting from the Motive of Duty." Philosophical Review 90 (3): 359-82.

Jamieson, Dale. 2007. “When Utilitarians Should Be Virtue Theorists.” Utilitas 19 (2): 16083.

Kagan, Shelly. 1991a. “The Appeal to Cost.” In The Limits of Morality. Oxford: Oxford University Press.

Kagan, Shelly. 1991b. "Précis of the Limits of Morality.” Philosophy and Phenomenological Research LI (4): 897-901.

Kamm, Frances. 1992. "Non-Consequentialism, the Person as an End-in-Itself, and the Significance of Status.” Philosophy \& Public Affairs 21 (4): 354-89. 
MacAskill, William. 2014. "The cold, hard truth about the ice bucket challenge." Quartz, 14 August (Accessed on 10 October 2014). Available at http://qz.com/249649/the-cold-hardtruth-about-the-ice-bucket-challenge/.

MacAskill, William. 2016. Doing Good Better. London: Guardian Faber Publishing. McElwee, Brian. 2017. "Demandingness Objections in Ethics." The Philosophical Quarterly 67 (266): 84-105.

McMahan, Jeff. 2017. "Doing Good and Doing the Best.” In Philanthropy and Philosophy: Putting Theory into Practice, Paul Woodruff, ed. New York: Oxford University Press. Mogensen, Andreas, Will MacAskill, and Toby Ord. 2017. “Giving Isn’t Demanding.” In Philanthropy and Philosophy, Paul Woodruff, ed. New York: Oxford University Press. Nussbaum, Martha. 1992. "Human Functioning and Social Justice. In Defense of Aristotelian Essentialism.” Political Theory 20: 202-46.

Pummer, Theron. 2016. "Whether and Where to Give," Philosophy \& Public Affairs 44 (1): 77-95.

Rawls, John. 1971. A Theory of Justice. Cambridge: Harvard University Press, rev. ed. 1999. Sachs, Ben. "Demanding the Demanding", Chapter 9, this volume.

Scanlon, Thomas. 1998. What We Owe To Each Other. Cambridge: Harvard University Press.

Sen, Amartya. 1980. “Equality of What?” In Tanner Lectures on Human Values, Stanley McMurrin, ed. Cambridge: Cambridge University Press.

Singer, Peter. 1972. "Famine, Affluence and Morality.” Philosophy \& Public Affairs 1: 229_ 43.

Singer, Peter. 2015. The Most Good You Can Do. New Haven: Yale University Press. Unger, Peter. 1996. Living High and Letting Die: Our Illusion of Innocence. New York: Oxford University Press. 